\section{International Scientific Journal Theoretical \& Applied Science}

\author{
p-ISSN: 2308-4944 (print) e-ISSN: 2409-0085 (online) \\ Year: $2015 \quad$ Issue: $01 \quad$ Volume: 21 \\ Published: $30.01 .2015 \quad$ http://www.T-Science.org
}

Zhanna Shapaevna Kenzhalina

$\mathrm{PhD}$, Docent, Department of "Economics" New Economic University named after T. Ryskulov,

Kazakhstan

ken_zhanna@mail.ru

Gaukhar Bisultanovna Amangaliyeva LL.M., Docent, Head of the Law Department Member of the scientific laboratory "Cross-cultural communication"

Almaty Management University, Kazakhstan

SECTION 31. Economic research, finance, innovation, risk management.

\title{
FORMATION OF THE MECHANISM OF PRODUCT QUALITY MANAGEMENT
}

Abstract: This article discusses the basic directions of the quality management system based on the analysis of the main indicators of company activity and product quality.

Key words: quality, competitiveness of indicators, Kaizen system, tomato paste, quality management.

Language: English

Citation: Kenzhalina ZS, Amangaliyeva GB (2015) FORMATION OF THE MECHANISM OF PRODUCT QUALITY MANAGEMENT. ISJ Theoretical \& Applied Science 01 (21): 150-155. doi: http://dx.doi.org/10.15863/TAS.2015.01.21.26

\section{Introduction}

In his annual message 'Kazakhstan's way 2050: a common goal, common interests, common future" from 17.01. 2014, the President of the Republic of Kazakhstan Nazarbayev N. A. determined that "Small and medium sized business development is the main tool for the industrial and social modernization of Kazakhstan in the XXI century. In this respect, my position, as it is known, is well defined, and I have expressed it many times. The greater the share of small-to-medium-sized businesses in our economy is, the more developed and sustainable Kazakhstan will be. Currently we have more than 800,000 small-to-medium-size enterprises employing 2.4 million of our citizens. Production in this sector has increased 1.6 times over the past four years and equals more than 8.3 billion tenge" $[1$, p. 1].

The country is implementing the second phase of the State program of industrial-innovative development, in the frame of which the realized goal is devoted to the improvement of products quality produced by the native enterprises [2].

Competitiveness of products of the processing enterprises depends largely on the quality of products, which includes a set of different features of product [3]. Let us conduct a research of products quality on the example of the LLP "Qing-Kaz".

LLP "Qing-Kaz" is the largest producer of tomato products in Kazakhstan. The share of the company in the Kazakhstan market is $40-45 \%$ of its capacity (data of the analytical center and marketing research of the JS "KazAgroMarketing”).

The company was founded in 1998. The first consignment of tomato paste was produced in 2000 . In order to ensure the production of their own carton packing, in 2005 the company opened a new plant for the production of metal cans for canning with the production volume of 2 million cans per year.

In 2006, the company implemented a quality management system for compliance with MC ISO 9001: 2000 and it was certified by one of the leading certification bodies worldwideDQSQUALITYSISTEMS (German Quality System) [4].

In 2009, the company implemented and certified food safety system for compliance with the international standard ISO 22000 at the expense of the budget program 056 "Improving the competitiveness of agricultural products"

The development of new products is held on the permanent basis, in order to expand the range of products. LLP "Qing-Kaz" produces more than 15 types of products (tomato paste, 6 sorts of ketchup, adjika sauces, tomato sauces, pickles, jam), with productivity rate exceeding 500 tons per month.

All "Qing-Kaz" products are made from the selected sorts of tomatoes "Red Star", which give the product a thick consistency, bright red color and a unique taste.

By the type of raw material, the product belongs to the canned fruits and vegetables, under the regime of thermal processing-to 
pasteurized/sterilized, according to the use-for the first and the second courses.

The use of a universal production line for bottling and accepted small-volume (more than 30 items) and easy-to-use product assortment meets the modern demands of the market. Products of the trademark "Qing-Kaz" is packaged in different types of packaging: glass and tin ones, polymer laminated packaging "Doy-pack". Production of 500 grams of plastic bottles was established in 2008

The company's products are sold in 42 regions of Kazakhstan through the official distributor. Today, the company is seeking the opportunity to enter their products to the markets of near and far abroad, in the framework of export policy of the company.

The company was marked with high awards at international, regional, national exhibitions and professional degustation for the achievements in the field of product quality.

The technological process of production complies with the requirements of the Quality Management System. The process of tomato paste production, sauces "Adjika", "Adzhika the sweet", tomato sauce, pickles, and jams is the canning process, which includes thermal treatment of the product placed in a hermetically sealed container. Competitiveness of the product largely determines the financial and economic condition of the enterprise. Here are some data of the enterprise.

Analysis of technical and economic data of LLP "Qing-Kaz" showed that the company was developing dynamically within the period of 2010 and 2013. This is evidenced by an increase in income from sales of products with 1031554113.94 to 1258213853.58 tenge, i.e. by $21.6 \%$. New products were produced and range of products was expanded. At the same time, in the same period, there was a decline of cumulative profit; the decline was 56, $35 \%$. The output per worker of the company increased by $21.9 \%$, which indicates the effectiveness of management. A very important criterion for the progressive development of economic activity is the rate of profitability of sales, the value of which increased by 3.5 times at that period [5].

In order to analyze the financial stability of the organization, it is necessary to study the financial ratios. Coefficient of independency or concentrations of own funds determine the amount of share of funds invested in the activity of the enterprise by its owners. If the enterprise has higher ratio it will be more financially stable, stable and independent from the external creditors. On the analyzed enterprise, the value of this indicator is below the regulatory minimum. So, in 2011, the independent coefficient was 0.165 , which increased to 0.183 in 2013. The current dynamics indicates that LLP "Qing-Kaz" is dependent on foreign creditors. However, there is a positive trend. Consequently, the management of the company is gradually trying to overcome the current imbalance [5].

Dependency ratio exceeds the recommended value more than 2 times. In 2011 it was 0.834 , and in 2013-0.816. Analysis of the dependency ratio shows that the value of this index is high. This indicates that the assets of the company are funded by borrowings. The highest share of borrowings reduces the paying capacity of the company, undermining its financial stability and thus, reduces the credibility of counterparties and reduces the possibility of obtaining a loan. However, it is worth noting that the dynamics of the dependency ratio has the decreasing tendency [5].

Coefficient of maneuverability shows what proportion of equity sources is in the mobile form. The coefficient of maneuverability on the analyzed enterprise was 1, 500 in 2011 and decreased to 1,092 in 2013. In order to calculate the maneuverability we determined the size of own working capital as the difference between current assets and current liabilities.

To evaluate the liquidity and solvency of the company it is necessary to calculate the indicators characterizing the cash in the pay office and current accounts at the bank, as they express the totality of cash, that is, property that has an absolute value. These resources are the most mobile; they may be included in the financial and business activities at any time. The art of the financial management is to keep the minimum required amount of funds on the accounts, and the other part that may be needed for current operations can be in the quick assets.

Indicators of liquidity allow determining the ability of the company to pay its short-term liabilities, realizing its current assets.

An enterprise may be liquid in a bigger or smaller degree, as the current assets include diverse working capital, among which there are both easy to implement and hard-to-sell ones for foreign debt retirement.

Analysis of profitability indicators of LLP "Qing-Kaz" showed that overall cost effectiveness has a positive dynamics. In particular, the size of cost effectiveness increased from $1.79 \%$ in 2011 to 6.36 $\%$ in 2013. In 2013, in whole, the company improved its position, but at the same time, the management of the company should take measures concerning the more rational management of capital companies in order to increase the efficiency of financial and economic activity [5].

The quality of products is determined by its compliance with the quality standards.

The enterprise has:

- Certificate of System of Management № 358544QM08, as of 30.09.2009 issued by DQS $\mathrm{GmbH}$ (German certification system management) [4]; 
- Certificate of compliance to the system of Management of food safety № 09.814.026 as of December 1. 2009, issued by Certification Association "RUSSIAN REGISTER";

- Patent on the industrial model - polymer

laminated packaging "Doy-pack";

- Certificate on a trademark.

In 2008 the company participated in the regional competition - exhibition for the award of President "AltynSapa", and won the second place in the nomination "Best food"

In 2010 the $12^{\text {th }}$ Kazakhstan International Fair "Food: Industry -food and beverages, ingredients, equipment and packaging" marked the sauce "Cobra" with a Diploma for Quality.

Hygienic requirements for products are under control of the Sanitary Regulations «Sanitary and epidemiologic requirements for food products» № 611 as of 06.08.2010 [6; 7].

All products are certified.

Consumer properties of tomato paste and ketchup favorably compares to the native analogs:

Consumer properties of tomato paste and ketchup favorably compares to the native analogs:

1. homogeneous thick (concentrated) consistency;

2. a uniform throughout the mass brightly raspberry-red colored;

3. solids content:

-in the tomato paste $-24-25 \%$

-in ketchup till $18 \%$ (depending on the type of ketchup)

The products contain only natural ingredients; they do not contain dyes, synthetic food additives.

In recent years, the attention of scientists is focused on the other substance in tomatoes Lycopene. It is an organic compound, which gives a rich red color to the fruit; it is a very powerful natural antioxidant (according to its features it exceeds recognized vitamins $\mathrm{C}$ and $\mathrm{E}$ )

Antioxidant Lycopene in tomato prevents cardiovascular diseases as infarct and apoplexy, and it considerably reduces the risk of prostatitis and some forms of cancer of esophagus and stomach.

Physicians believe that regular consumption of tomatoes, tomato juice, tomato paste, ketchup and other tomato sauces can significantly reduce the risk of oncologic diseases. Lycopene is necessary and useful for smokers as a protective mean.

Tomatoes keep their unique features after thermal conditioning or canning. Moreover, it is considered that they become more useful as the ingredient of sauces or vegetable stew.

Industrial laboratory with the necessary set of equipment allows both controlling the quality of use of draw materials and the output of ready products at a high level.
Laboratory of the enterprise makes analyses concerning the physical and chemical characteristics of water and the produced products.

In accordance with the contract, the accredited laboratory studies indicators of product safety and water (microbiology, radiology, toxicity).

The quality of products is controlled in accordance with the requirements of international standards ISO 9001 and ISO 22000 [6; 7].

In order to run the requirements of the documented procedures, the enterprise defines the processes on controlling the produced products:

The process of "control of quality" consists of the lower-level process (sub processes):

- incoming inspection of raw materials, ingredients, packaging and food additives;

- quality control of products and technology parameters;

- quality control before the realization of

product;

- analysis and improvement.

The enterprise has implemented and is maintaining in the working condition the PNP (preliminary necessary programs), according to ISO 22000:

- maintenance of sanitary environment at all stages of production;

- maintenance of personal hygiene of staff, knowledge and skills;

- maintenance of infrastructure;

- identification, calculation and preservation of raw materials;

- control of production by laboratory;

- requirements of regulatory document, technological instructions and recipes to the relevant products, as well as the results of the product development process;

- technical regulation №541 dated June 6, 2008, which is harmonized with international standards such as ISO2200: 2005, ISO \TS 22004: 2005, ISO 2169: 1981, ISO 6949: 1988, as well as standards of the Republic of Kazakhstan for tomato products are harmonized with the standard of the Commission Alimentarius Codex;

- CODEX STAN 57-81.

The company carries out the analysis of customers' feedback. Thus, the questionnaires were received from customers from 10 regions: Kokshetau, Ridler, Shymket, Semipalatinsk, Lisakovsk, Astana, Taldykorgan, Aktau, Kostanay, and Taraz. The analysis has shown a high appreciation of our customers; the respondents put an "excellent" grade for the taste characteristics of the product.

Analysis of questionnaire of customers showed that the product of enterprise becomes more and more in demand on the market, and customers give preference to this product. Let us make SWOT analysis of the enterprise. 
SWOT analysis is one of the most common methods of management practices, which connects internal and external factors that determine the development of the organization.

The purpose of the SWOT analysis of the project is to identify and define the ways of development of the strengths of the project, to identify opportunities for the successful use of the existing and to create new opportunities. It allows taking into account the existing weaknesses in order to reduce their impact on the development, and to neutralize the threat.

SWOT analysis

\section{Strengths}

The strengths of the project are in the steady demand for tomato paste to the public in regard to the developing market on ketchup and other tomatobased products in Kazakhstan, and according to the data of Qing Kaz Company, the sales of these products is increasing annually.

Qing Kaz has the largest market share of 53\% in the Kazakhstan market of tomato paste. It is worth noting that the share of the second largest player in the market is $10 \%$, which in turn indicates the strong position of Qing Kaz Company in Kazakhstan.

The official distributor of the Qing Kaz has covered $100 \%$ of Kazakhstan territory.

For more than 10 years of its history the trademark of Qing Kaz is known by customers as the most popular, which in its turn is confirmed by the company's share on the market of tomato products.

\section{Weaknesses}

The strong dependence of producers on import of concentrated tomato paste from CPR can be distinguished as a weakness. Dependence on only one supplier of raw materials in the case of entry tariffs, or introduction of non-tariff limitations on import has a risk to negatively impact on the production of the finished product for Qing Kaz.

In spite of the availability of space for the further rise of sales of ketchup, market for the basic product of tomato paste is compact and the further extension is accompanied with difficulties.

Opportunities:

The project is enlisted into the number of priority sectors of economy for the program implementation "Productivity 2020" [8, p.7]. While adhering the requirements by the participants, the Program Initiator might receive privileges in the form of interest reduce on leasing of equipment to 7 , $5 \%$.

Expanding of export opportunities for the producer, realization of probation supplies to Afghanistan in particular, as well as the readiness of local distributor to continue cooperation with Qing $\mathrm{Kaz}$, opens the new trade area of the product for producer. Moreover, there are negotiations, which are held by the Qing Kaz about supplies of products into the Southern parts of Russian Federation.
The company also does the work on widening of assortment of the manufactured products, which in its turn opens opportunities of access to the external market.

\section{Threats}

The presence of bigger produces of tomato paste from the member-states of Customs Union on the market of Kazakhstan is distinguished as a threat. In the case of intensification of competition, transnational companies having access to bigger financial funds may greatly decrease the competitive opportunities of Qing Kaz on the markets.

For this exactly enterprise, this risk is considered as a moderate one, since the present competitors on the market are mainly not concentrated on the production of tomato paste, making the accent on souses with the higher value added tax.

The increase of import fees for the raw materials from the external markets for countrymembers of Customs Union can serve as not less serious factor of risk.

This sort of risk for the enterprise is considered as a moderate one, since nowadays, the question of fees' increasing on tomato concentrate from foreign countries is not taken into account by the countrymembers of Customs Union.

Nevertheless, the producer should notice the diversification of raw materials' supply in a middle term perspective.

Ways of improvement of management for the product quality

The introduction of new equipment was suggested in order to improve the quality of business processes and their compliance with the international standards.

The question of automation of technologic process at all stages of production in modern manufacturing is as relevant as ever. Therefore, it is necessary to invest a lot of money into the modernization of the equipment in order to improve the production.

New technologies are planning to be introduced in order to solve these problems:

1) Installation of water-purification system - the technological process that is carried out in the processing of natural water in order to bring it to the required quality standards of water consumption.

Cleaning of water is intended to improve the taste of water (removal of the chlorine, odor, smack, organic compounds, microflora, etc)

2) Production of a multilayer plastic bag with the use of brand mark SCJ -MP 55D

Now, in order to provide the enterprise with its own packing material, it produces plastic bottles for bottling ketchup. The development of the plastics processing industry and the development of new 
types of raw materials allow transforming the process of creating of new types of packages into the creative process. Considering it, we are planning to introduce a new technology of producing a multilayer plastic bottle with the use of the latest materials at the enterprise.

Manufacturing of a multilayer plastic packaging uses the beneficial properties of different materials. In fact, having a set of polymers with different characteristics, any structure can be created in accordance with the needs of market and the task of the producer.

The enterprise plans to use the new material EVON (copolymer of ethylene and vinyl spirit) in order to manufacture the multilayer packaging. Within the input of this material into the structure of polymer packaging, we get a transparent cover with the barrier characteristics at the level of aluminum.

The bottle contains five layers and guarantees the safety of the product without preservatives for up to 18 months. According to the period of storage such packaging does not inferior to a glass bottle, close to it in transparency, and it weighs 10 times less.

In future, this package might be used for bottling of tomato paste.

3) The use of robotic systems of continuous action in the process of automatic packaging of products

The group packaging of glass bottles is carried out more effectively by the continuous robotic systems in the high-speed bottling lines with the output of more than 10,000 cans per hour.

The chosen system VANTA (company Guangzhou Vanta packing machinery) gives the opportunity of loading products into the cardboard box in an automatic regime. The cardboard box itself folded up automatically by the robot-loader of boxes.

The main factor here is given to the way of loading the product into package. The loading of product into the cardboard box is done by the robotloader.

The main parts from the companies Siemens, Schneider, Danfos.

4) The process of automatic control and regulation of technological parameters in "on-line" regime

Due to technology of "non-contact manufacturing", all the processes of technological parameters will be fully computerized.

Expected results:

- Improvement of a quality of product in the result of cleaning of water, used in the process of cooking products.

- The issue of a new type of multilayer polymer package, the quality of which is not inferior to the traditional glass bottle, but much more chipper in price, which finally will reduce the net cost of the product.

- Decreasing of the production wreck because of the exact adherence of technological regimes by operators in a mode of automatic control and regulation.

- Reducing of job places:

- in the control process of technological regimes at the expense of introducing ASM (at the present time 4 operators can be reduced to 1 unit)

- in the process of putting into a transportation package with the help of robotic equipment using (reduction of 6 loaders).

- Increase of productivity and workability of an operator not attracting his attention on recording and control of a temporal interval of the same type of technological operations.

The exact adherence of definite technological steps and realization of important parameters is a prerequisite of a high quality of profitability.

With entry of Kazakhstan into the Customs Union, the competition on the market of sales between local and Russian producers has increased.

To stimulate the purchase of "Qing Kaz" goods mini-markets have developed and launched the "Partner" merchandizing program in the enterprise.

The aim of the "Partner" merchandizing program is:

- increase of sales in retail centers of " $\mathrm{B}$ " and

"C" categories by:

- improvement of quality distribution;

- preservation and increase of the share and place on the shelves;

- increase of goods' reserves in trade centers;

- adherence of pricing policy.

To realize the programs the following measures are conducted:

- doing the survey on trade centers with the aim to reveal potential participants;

- signing treaties for conducting this program;

- development and coordination of the system of bonuses with trade centers;

At present time, it is necessary not only to support, but also to develop further and to improve the existing systems of management using the requirements of the International Standard of ISO 9001 and to introduce the system of Kaizen as well.

Kaizen - is a Japanese strategy of continuous perfection (production without losses) [9].

Kaizen - management has two main components:

1. maintenance of level,

2. perfection 
The maintenance function is directed on providing adherence to existing technological, managerial and production standards. Perfection function is aimed at improving existing standards.

" $5 \mathrm{C}$ " - is a system of involvement of the entire team in a regular activity of ordering, cleaning and strengthening of the discipline on the job place. Its realization helps to increase the productivity of workers' labor, decreases the amount of wreckage and finally saves time and money of the company [9].

The main work on expanding the size of export is a search of potential clients beyond Kazakhstan borders. Today production of Qing Kaz is exported to Afghanistan.
One more step in this direction is the establishment of branches in Russia -«Prima Distribution» is an official distributor in Kazakhstan. At present time the treaty with JSC "Kazakhstani International Trade and Raw Material Universal Stock Company «El Kazyna» is under construction for searching potential clients in Russia.

The main principle of advertising policy of the enterprise is an aggressive trade-marketing permanent stimulation of trade centers for purchasing the production of LLP "Qin-Kaz" that helps objectively planning and organizing the work to increase the sales. As far as the experience showed the advertising policy of such a kind is maximally efficient to achieve the goals of the enterprise

\section{References:}

1. (2014) Poslaniye Presidenta RK N.A. Nazarbayeva "Kazakhstanskiy put - 2050. Yedinaya Tsel, edinye interesy, yedinoye budushee" ot 17.01. 2014

2. (2010) The State Program of Forced Industrial Innovative Development of the Republic of Kazakhstan. 2010

3. (2012) Marger B.Ye. Upravleniye kachestvom. Uchebnoye possobiye INFRA-M, 2012, 176 s.

4. (2014) Dqs quality sistems (nemetskaya Sistema kachesnva)

5. (2013) Otchet o pribyli I ubitkakh, balans TOO "Qing Kaz" 2011-2013

6. (2010) Sanitarnye pravila "sanitarnoepidemeologicheskiye trebovaniya $\mathrm{k}$ pishevoi produktsii” №611 ot 06.08.2010.
7. (2001) Sustemy menedzhmenta kachestva. Osnovnye polozheniya. "Slovar"/Standarty RK ISO 9000-2001. - Astana, 2001. - $180 \mathrm{~s}$.

8. (2010) Gossudarstvenaya Programma "Proizvoditelnost 2020" 2010

9. Maassaki Imai Kaidzen (2011) Kluxh k uspekhu yaponskikh kompaniy. Izd. Alina Publisher, 2011

10. Kenzhakina Zh. Sh. (2014) Van Min Sozdaniye effektivnoy sistemy upravleniya kachestvom na predpriyatii, osnovi economiki, № 1-2 2014 